\title{
Refractive error scenario in paediatric age group (7-15 years) in Assam: A hospital based study
}

\author{
Harsh Vardhan Singh ${ }^{1, *}$, Dileep Kumar ${ }^{2}$ \\ ${ }^{1}$ M.S. Ophthalmology, Dept. of Ophthalmology Regional Institute of Ophthalmology, Guwahati, Assam, ${ }^{2}$ Consultant Surgeon, Udayachal \\ Charitable Eye Hospital, Rajnandgaon, Chhattisgarh, India \\ *Corresponding Author: Harsh Vardhan Singh \\ Email: hvsc008@gmail.com
}

\begin{abstract}
Aim: To study the prevalence of various types of Uncorrected Refractive errors in a paediatric age group (7-15 years) attending a tertiary care centre.

Materials and Methods: A hospital based cross sectional study was carried out to evaluate proportion of various types of uncorrected refractive errors in age group of 7-15yrs. in a tertiary eye care centre for a period of 3 months.

Total of 4000 children were screened for presence of refractive error after taking informed consent from their parents. Children were then grouped into different types of refractive errors based on the results of cycloplegic refraction.

Results: Out 4000 children, the most common age with refractive error was 10-12 years followed by 13-15 years and the commonest refractive error was astigmatism (55\%) followed by myopia (34\%). The most common presenting symptom was headache followed by visual disturbance. Significant family history was noted among group with prevalence of positive family history in $17 \%$ of study group.

Discussion \& amp, Conclusion: Astigmatism \&amp; Myopia is the commonest types of refractive error in children that was consistent with other Indian studies. Study suggests the significance of early school based screen to reduce the burden of childhood ocular morbidity because of uncorrected refractive error.
\end{abstract}

Keywords: Uncorrected refractive error, Childhood blindness, Assam, Scenario.

\section{Introduction}

Refractive error is one of the major contributors to preventable cause of blindness \& visual impairment. ${ }^{1}$ The estimated prevalence of visually impaired population is 3 percent of world's total population, which means that more than 180 million peoples belong to visual impaired group. Out of these, $33 \%$ of population is contributed by South East Asian Region. ${ }^{2}$ Refractive error is the second most common cause of treatable blindness accounting for about $20 \%$ of total visual impaired population after cataract in India. $^{3}$

Out of total 1.5 million blind children in world, 27 lacs reside in India. Since children do not usually complain of visual difficulties, early diagnosis and prompt treatment of eye diseases in these age group is crucial, as lack of self reporting of symptoms \& ignorance can lead to progression to irreversible cause such as amblyopia ${ }^{4}$. Poor vision especially in age group of 7-15 yrs. has adverse influence in child's development \& may lead to poor performance in school. Visual impairment because of refractive errors has huge economic burden in Indian and the knowledge about prevalence of various types of refractive error in pediatric age group (7-15yrs.) in different regions of India will be helpful in making proper strategy for eliminating this preventable cause of blindness.

The present study aims to estimate the prevalence of refractive error in age group of $7-15 y$ rs. attending the outdoor of RIO, Guwahati and analyzing the causes of uncorrected defective vision prevalent in this region.

\section{Materials and Methods}

Present study was hospital based cross-sectional study from July. 2015 to Dec. 2015. Ethical clearance for the study was obtained from ethical committee of GMCH. During this study period, 4000 children with refractive errors presenting in RIO, OPD were screened. Consent for the study was obtained from their parents. Proper history \& thorough ocular examination, including slit lamp examination, fundus evaluation \& cycloplegic refraction were carried out by trained ophthalmologist \& optometrist.

Exclusion Criteria: Children with coexisting organic eye diseases were excluded.

\section{Observation and Results}

Present study showed most common age group of refractive error to be $10-12 y r s$. (48\% of total) followed by $13-15 y r s$. (40\% of total) and the age group with least prevalence was among 7-9yrs. age group (12\% of total study population) [Table 1].

The commonest type of refractive error in the present study was Astigmatism (55\% of total) followed by Myopia (34\% of total) \& least being hypermetropia (11\% of total) [Table 2]. In our study refractive error was more common among female child with overall prevalence of $55 \%$ of total study group [Table 3]. Based on clinical types, myopic astigmatism ( $41 \%$ of total refractive error cases) followed by simple myopia (34\% of the total) was commonest in the study. While the maximum prevalence was among age group of 13-15yrs. \& 10-12yrs. [Table 4,5]. Among Myopic males the most common age group was $10-12$ yrs. (280 of $440 ; 66.6 \%$ of total Myopic male) followed by $13-15 y$ rs. group (160 of $440 ; 33.3 \%$ of total) while in females, most 
prevalent age group of myopia was $10-12 \mathrm{yr}$ group (480 of $960 ; 50 \%$ of total Myopic female) followed by $13-15 \mathrm{yr}$ of age (360 of $960 ; 37.50 \%$ of total). Hypermetropia was more common in males with maximum prevalence in 13-15yrs (120 0f 320; $37.50 \%$ of total Hypermetropic males). Astigmatism was maximum in 12-14yrs. age (1400 of 2640; $53 \%$ of total Astigmatism) followed by $10-12$ yrs age (600 of $2640 ; 22.72 \%$ of total).

The common presenting symptoms of uncorrected refractive error in present study were headache $(55 \%)$ followed by blurring of vision $(39 \%)$. Other symptoms like near vision defect, watering, redness, recurrent infection contributes only $6 \%$.

Associations of family history with uncorrected refractive error were noted in $17 \%$ in the present study with maximum association seen in male child. (24 out of 90 vs 10 out of 100$)$.
Table 1: Age wise distribution of study population

\begin{tabular}{|l|c|c|}
\hline Age in years & No of patients & Percentage \\
\hline 7 & 160 & $4 \%$ \\
\hline 8 & 160 & $4 \%$ \\
\hline 9 & 160 & $4 \%$ \\
\hline 10 & 680 & $17 \%$ \\
\hline 11 & 240 & $6 \%$ \\
\hline 12 & 1000 & $25 \%$ \\
\hline 13 & 640 & $16 \%$ \\
\hline 14 & 520 & $13 \%$ \\
\hline 15 & 440 & $11 \%$ \\
\hline
\end{tabular}

Table 2: Clinical types of refractive errors

\begin{tabular}{|l|c|c|}
\hline \multicolumn{1}{|c|}{ Clinical Type } & No. of patients & Percentage \\
\hline Myopia & 1360 & 34 \\
\hline Hypermetropia & 440 & 11 \\
\hline Astigmatism & 2200 & 55 \\
\hline
\end{tabular}

Table 3: Sex distribution of study population

\begin{tabular}{|l|c|}
\hline \multicolumn{1}{|c|}{ Sex } & No. of children \\
\hline Female & 2200 \\
\hline Male & 1800 \\
\hline
\end{tabular}

Table 4: Percentage of refractive errors

\begin{tabular}{|l|c|c|c|c|}
\hline Types of refractive errors & No. of males & Percentage & No. of females & Percentage \\
\hline Myopia & 560 & $14 \%$ & 800 & $20 \%$ \\
\hline Hyperopia & 120 & $3 \%$ & 320 & $8 \%$ \\
\hline Astigmatism & 1120 & $28 \%$ & 1080 & $27 \%$ \\
\hline Total & 1800 & & 2200 & \\
\hline
\end{tabular}

Table 5: Demographic profile

\begin{tabular}{|l|c|c|c|c|c|c|c|c|c|c|}
\hline \multicolumn{1}{|c|}{ Sex } & $\mathbf{7}$ & $\mathbf{8}$ & $\mathbf{9}$ & $\mathbf{1 0}$ & $\mathbf{1 1}$ & $\mathbf{1 2}$ & $\mathbf{1 3}$ & $\mathbf{1 4}$ & $\mathbf{1 5}$ & Total \\
\hline Male & - & 40 & - & 80 & 80 & 160 & 40 & 80 & 80 & 560 \\
\hline Female & - & 40 & 40 & 120 & 120 & 200 & 80 & 200 & 0 & 800 \\
\hline Total & 0 & 80 & 40 & 200 & 200 & 360 & 120 & 280 & 80 & 1360 \\
\hline
\end{tabular}

Table 6: Sex distribution of refractive errors

\begin{tabular}{|l|c|c|c|c|}
\hline Types of refractive errors & No. of males & $(\boldsymbol{\%})$ & No. of females & $(\boldsymbol{\%})$ \\
\hline Myopia & 560 & $14 \%$ & 800 & $20 \%$ \\
\hline Hyperopia & 120 & $3 \%$ & 320 & $8 \%$ \\
\hline Astigmatism & 1120 & $28 \%$ & 1080 & $27 \%$ \\
\hline Total & 1800 & & 2200 & \\
\hline
\end{tabular}

Table 7: Comparison of age and sex with myopia

\begin{tabular}{|l|c|c|c|c|c|c|c|c|c|c|}
\hline Sex & $\mathbf{7}$ & $\mathbf{8}$ & $\mathbf{9}$ & $\mathbf{1 0}$ & $\mathbf{1 1}$ & $\mathbf{1 2}$ & $\mathbf{1 3}$ & $\mathbf{1 4}$ & $\mathbf{1 5}$ & Total \\
\hline male & - & 40 & - & 80 & 80 & 160 & 40 & 80 & 80 & 560 \\
\hline Female & - & 40 & 40 & 120 & 120 & 200 & 80 & 200 & 0 & 800 \\
\hline Total & 0 & 80 & 40 & 200 & 200 & 360 & 120 & 280 & 80 & 1360 \\
\hline
\end{tabular}

Table 8: Comparison of age and sex with hyperopia

\begin{tabular}{|l|l|l|l|l|l|l|l|l|l|l|}
\hline Sex & $\mathbf{7}$ & $\mathbf{8}$ & $\mathbf{9}$ & $\mathbf{1 0}$ & $\mathbf{1 1}$ & $\mathbf{1 2}$ & $\mathbf{1 3}$ & $\mathbf{1 4}$ & $\mathbf{1 5}$ & Total \\
\hline male & 40 & - & - & 40 & - & 120 & 40 & - & 80 & 320 \\
\hline female & - & - & - & 40 & - & 40 & - & - & 40 & 120 \\
\hline total & 40 & - & - & 80 & - & 160 & 40 & - & 120 & 440 \\
\hline
\end{tabular}


Table 9: Breakup of astigmatism into different groups

\begin{tabular}{|l|c|c|}
\hline Types & No of children with error & Percentage \\
\hline Simple hypermetropic astigmatism & 280 & $7 \%$ \\
\hline Compound hypermetropic astigmatism & 200 & $5 \%$ \\
\hline Simple myopic astigmatism & 840 & $21 \%$ \\
\hline Compound myopic astigmatism & 800 & $20 \%$ \\
\hline Mixed astigmatism & 80 & $2 \%$ \\
\hline Total & 2200 & $55 \%$ \\
\hline
\end{tabular}

Table 10: Clinical symptoms with respect to sex

\begin{tabular}{|l|c|c|c|}
\hline \multicolumn{1}{|c|}{ Symptoms } & Male & Female & Total \\
\hline Diminution of vision & 800 & 760 & 1560 \\
\hline Headache & 880 & 1320 & 2200 \\
\hline Others & 120 & 120 & 240 \\
\hline
\end{tabular}

Table 11: Family history present in the total study group

\begin{tabular}{|l|c|}
\hline \multicolumn{1}{|c|}{ Family History } & Percentage \\
\hline Yes & $17 \%$ \\
\hline No & $83 \%$ \\
\hline
\end{tabular}

\section{Discussion}

In present study, 55\% of refractive error were either simple myopic (34\%) or simple myopic astigmatism $(21 \%)$ followed by compound astigmatism $(25 \%)$ \& hypermetropia (16\%), similar results were noted in GP Kantha et al. ${ }^{8}$ Padhye et al reported similar results in their study. They have also reported the prevalence of myopia, hypermetropia and astigmatism was $1.45 \%, 0.39 \%$ and $0.21 \%$, respectively in the child rural population. In their study simple myopia was more prevalent. ${ }^{5}$

In the study refractive error among girls were more as compared to prevalence among boys \& which was consistent with other Indian studies. ${ }^{6,7}$ In present study, most common age group presenting with refractive error was $10-12$ yrs. followed by $13-15 y$ ys, which was consistent with other Indian studies. ${ }^{8-10}$ Present study demonstrated presence of family history of refractive error in $17 \%$ of study population; similar association was noted in Prema et al study. ${ }^{11}$

\section{Conclusion}

Refractive error is quiet common among school going children especially in developing countries like India \& large fractions of cases remain undiagnosed \& never report to the hospitals. Early diagnosis \& simple interventions like glass correction can reduce the burden of preventable cause of blindness in these age group.

\section{Conflict of Interest: None}

\section{References}

1. World Health Organisation. Preventing blindness in children: Report of WHO/FAPB scientific meeting, Geneva. WHO 2000 In: Gilbert C., Foster A., Childhood Blindness in the Context of vision 2020 the right to Sight. Bulletin. 2001;79:227-3.

2. Pascolini D, Mariotti SP. Global estimates of visual impairment: 2010. Br J Ophthalmol. 2012;96:614-618.
3. K Park, Parks Textbook of Preventive and Social Medicine, $23^{\text {rd }}$ edition, 2014.

4. Nwosu SNN. Childhood Eye Diseases in Anambra State, Nigeria. Nigerian Journal of Ophthalmology. 1999;7:34-8.

5. Ref:Amruta S. Padhye, Rajiv Khandekar, Sheetal Dharmadhikari et al. Prevalence of Uncorreted Refractiv e Error and Other Eye Problems among Urban and Rural School Children. Middle East Afr J Ophthalmol. 2009;16(2):69-74.

6. Rahman M, Devi B, Kuli JJ, Gogoi G. A study on the refractive status of school going children aged between 10 to 15 years in Dibrugarh Town, Assam, India. IOSR J Dent Med Sci. 2015;14:27-33.

7. Nisha Dulani, Harish Dulani. Prevalence of Refractive Errors among School Children in Jaipur, Rajasthan. International Journal of Scientific Study. 2014;2(5).

8. GP Kantha, Sonam Sethi. Prevalence of refractive errors in school children (12-17 years) of Ahmedabad city. Indian Journal of Community Medicine. 1987;24:23-30.

9. Yingyong P. Refractive errors survey in primary school children (6-12 years old) in 2 provinces: Bangkok and Nakhonpathom (one year result). J Med Assoc Thai. 2010;93:1205-10.

10. Rahman M, Devi B, Kuli JJ, Gogoi G. A study on the refractive status of school going children aged between 10 to 15 years in Dibrugarh Town, Assam, India. IOSR J Dent Med Sci. 2015;14:27-33.

11. Prema. N. Prevalence of refractive error in school children. Indian Journal of Science and Technology. 2011;4:1160-1161.

How to cite this article: Singh H. V, Kumar D. Refractive error scenario in paediatric age group (7-15 years) in Assam: A hospital based study. Int $\mathbf{J}$ Ocul Oncol Oculoplasty. 2018;4(4):148-150. 